\title{
A dor de amor na medicina da alma da primeira modernidade*
}

Paulo José Carvalho da Silva

Este artigo discute o problema da dor de amor nos diferentes campos do saber que compunham a medicina da alma da primeira modernidade. Deu-se especial destaque às reflexões do médico francês Jacques Ferrand (1575-1623) sobre o caráter instável, ilusório e faltoso do amor. Conclui-se que a dor de amor exige pensar as relações entre os afetos e o corpo, além de desafiar as próprias categorias diagnósticas e os tratamentos tradicionais.

Palavras chave: Dor de amor, melancolia, ciúme, medicina da alma, história da psicopatologia

* Pesquisa realizada com apoio da Fapesp. 
As dores de amor, que suscitam tantas lágrimas nos divãs dos analistas, são um tema recorrente na cultura ocidental. Apesar de ser matéria muito explorada do ponto de vista literário, há poucas discussões históricas sobre os tormentos do amor (Altbauer-Rudnik, 2006, p. 34). Muitos discursos, identificados como parte da antiga tradição da medicina da alma, afirmam que o amor não correspondido, frustrado ou impedido dói, e muito, no corpo e na alma. Proponho, então, analisar alguns exemplos de autores da primeira modernidade que refletem sobre a natureza instável, faltosa e perturbadora do amor.

Engana-se quem pensa que se trata de um problema exclusivo dos artistas e poetas. Em um sermão pregado no Convento de Odivelas, no ano de 1644, padre Antônio Vieira discorre sobre os mais poderosos e perigosos afetos da vontade humana: o amor e o ódio. Nele, Vieira condena o amor mundano. Para ele, o que no mundo se chama de amor, na realidade, não existe. Não passa de ilusão, quimera, mentira, engano, doença da imaginação. Por tudo isso, o amor é tormento. O amor humano é fonte de dores da alma porque é da ordem da dúvida e, sobretudo, da incerteza de ser correspondido:

Póde haver maior tormento que amar, quando menos, em perpetua duvida, amar em perpetua suspeita de ser, ou não ser amado? Pois este é o inferno sem rendempção, a que se condemnam todos os que amam humanamente, e tanto mais, quanto mais amarem. (v. II, p. 307)

Ao retomar a afirmação dos Cânticos (VIII, 6: Fortis est ut mors dilectio, dura sicut infernus aemulatio) segundo a qual o amor é forte como a morte e o ciúme, cruel como o inferno, Vieira qualifica o amor humano de infernal. Ele afirma que o amor promete o paraíso, mas é uma morte pela qual sempre se vai ao inferno.

Se existisse, o paraíso do amor seria amar e ser amado, com a certeza desse amor nunca acabar em ódio. Mas neste mundo não há esse amor, nem essa certeza. Há dúvidas, desconfianças e re- 
ceios. Há suspeitas se me amam ou não me amam; se já me amam menos do que antes, se trocam o meu amor por outro ou se outro pretende roubar o meu amor etc. Em outras palavras, o amor humano está condenado ao ciúme, que é um tormento cruel, pois duvidoso, fixo na imaginação e nunca satisfeito.

No "Sermão do Mandato", pregado no Hospital Real de Lisboa, em 1643, Vieira chega a afirmar que mais mortal do que as enfermidades do corpo é o amor humano. Portanto, ele discorre sobre os quatro remédios do amor: o tempo, a ausência, a ingratidão e, sobretudo, o melhorar de objeto.

O tempo tira do amor a novidade e ele enfraquece. O amor humano também não resiste à ausência, que tem o poder de esfriá-lo, porque tira a "comunicação com o objeto". A ingratidão subtrai o motivo. Um amigo ingrato não apenas se torna indigno do amor, como também merecedor do ódio. Finalmente, o mais eficaz remédio do amor seria o melhoramento do objeto. Ou seja, trocar o objeto humano pelo divino. Esse seria amor fino, perfeito e incurável. ${ }^{1}$

Antônio Vieira realiza uma interpretação, modulada pelo catolicismo contrareformado, dos remédios do amor propostos por Ovídio (43 a.C.-17) em seu $O s$ remédios do amor. O poeta latino propunha, para esquecer a pessoa amada, uma vida ativa, mudar de cidade, refletir sobre os defeitos da tal pessoa ou comparála a alguém mais bela, ter várias amantes, pretender-se frio e indiferente, meditar sobre os tormentos do amor, fugir da solidão, evitar o convívio com casais enamorados, evitar encontrar-se com a pessoa amada, não reclamar, não cultivar o ódio ou as doces lembranças, ficar longe dos concertos, danças, peças de teatro e, sobretudo, dos banquetes e do vinho que estimulam a paixão erótica.

Os argumentos de Vieira (1643) convergem, porém, para um questionamento sobre a própria natureza do amor: o que é, afinal, esse afeto que pode ser curado? Vieira chama o amor humano de fraco, inconstante e imperfeito: "O amor, a quem remediou, e pôde curar o tempo, nem poderá ser que fôsse doença; mas não é amor" (v. IV, p. 295).

De qualquer forma, o que interessa no receituário para os males do amor proposto por Vieira nesse sermão é a concepção segundo a qual o amor humano aproxima-se mais da dor do que do prazer. É um amor que não é amor, e sim mal a ser remediado, uma dor da alma.

No "Décimo Nono Sermão do Rosário", Vieira (s/d.) critica a característica do amor de tudo prometer e somente cumprir parcialmente. $\mathrm{O}$ amor humano é sempre parcial, por isso, triste. É um limite do próprio amor, não daquele que

1. Sobre essa oposição entre o amor humano e o amor fino de Cristo e os remédios do amor propostos por Vieira, ver R.M. Assis, A fineza do amor nos sermões do mandato do Padre Antônio Vieira, em Massimi e Silva, 2001, p. 65-77. 
ama. Não importa se o sujeito do amor é rico ou pobre, humilde ou poderoso, no ato de dar-se há inevitavelmente divisão e na divisão, parcialidade:

A maior inclinação do amor é dar ou dar-se todo; e a maior mortificação do mesmo amor é dar sómente parte. (...) Assim se entristece e mortifica o amor, quando dá parte a quem quizera dar tudo. Mas d'esta mortificação nenhum amor póde se livrar, ainda quando o maior amor se ajunta com o maior poder. (v. XII, p. 51-52)

\section{Amor humano, amor de dor}

Para Túlio Cícero (106-43 a.C.), a paixão amorosa pode ser uma enfermidade da alma. Nas Tusculanae Disputationes (IV), lê-se que é vergonhoso estar fora de si ao gozar os prazeres do amor, do mesmo modo que é infame desejálos com ardor. Ele considera o amor uma futilidade perigosa. Nas comédias gregas, ele é a causa das loucuras e dos excessos. Nas tragédias, o amor faz nascer as maiores infelicidades.

Um amor sem inquietude, sem desejo, sem preocupações ou suspiros seria ideal, enquanto a paixão amorosa é a mais violenta das paixões humanas. Sem considerar a corrupção, o adultério, o incesto, entre outras vergonhas provocadas pelo amor, por si só, a perturbação da alma que ele causa é suficiente para qualificá-lo de não natural e irracional.

Como não há paixão sem ser objeto da opinião, sem ser admitida pelo julgamento e sem ser voluntária, o remédio para o amor, segundo Cícero, é uma correção nas faculdades da alma afetadas. Em suma, é preciso mostrar como o objeto do amor é enganoso, desprezível e sem valor ou mesmo mostrar como é possível obter a mesma satisfação de outro modo, com outros gostos ou em outros ambientes. Considera-se também que um novo amor cura um antigo. Todavia, deve-se, sobretudo, mostrar que o amor é uma loucura.

A oposição entre o amor humano e o amor a Deus, de modo a enfatizar o caráter contraditório e inconsistente do amor entre os homens, já se encontrava no pensamento de Agostinho (354-430) que, inclusive, é bastante citado por Antônio Vieira. No livro IV das Confissões, ele pondera que a violência da dor que sentira ao perder seu amigo de infância devia-se ao excesso de amor humano. Com sua morte, dominava-o um pesado tédio de viver e um medo de morrer. Quanto mais amava o amigo, mais odiava e temia a morte. Ele ratifica a idéia poética de que o amigo é metade da alma, e afirma ter sentido um horror à vida ao se ver obrigado a continuar vivendo subtraído de sua metade. Inquietava-se, suspirava, chorava, perturbava-se sem descanso nem circunspecção. Quando o 
tempo diminuiu sua dor, ele pôde concluir que todo o seu sofrimento ocorreu porque amou um mortal como se ele não houvesse de morrer. Enfim, para Agostinho, a amizade humana é inconsistente: quem ama humanamente está sujeito às trevas das dores, pois só não perde nenhum amigo aquele a quem todos são queridos n'Aquele que nunca perdemos.

Conforme outra influência fundamental para Vieira e os pensadores ibéricos da primeira modernidade de modo geral, Tomás de Aquino (1228-1274), na Suma Teológica (Questão XXVI e seguintes), chama-se amor o princípio de movimento tendente para o fim amado. Por essa razão, não há nenhuma paixão que não se fundamente no amor, porque todas as paixões da alma implicam movimento ou repouso relativamente a algum objeto. O amor causa o desejo, a tristeza, o prazer e, por conseqüência, todas as outras paixões.

Quanto aos efeitos nocivos, em específico, Tomás discute se o amor é ou não paixão lesiva. Admite que o amor causa desfalecimento ou langor, na ausência do objeto amado. Ele também provoca o derretimento, que é justamente o contrário do congelamento do coração, em sua ausência. E por último, mas nem por isso menos perigoso, o amor causa o fervor ou desejo intenso. Por outro lado, o amor pode ser perfectível por meio do melhoramento do objeto.

Houve também quem afirmasse que o amor pode ser uma peste. As dores do seu amor impossível por Laura são descritos por Francesco Petrarca (13041374), além dos seus poemas, no Secretum, obra na qual o grande humanista, que empreende a campanha pela legitimidade da poesia sobre o amor mundano, pondera melancolicamente sobre a solidão e as dores da alma humana confrontada com seus quereres e limites. No terceiro livro, que corresponde ao terceiro dia do diálogo imaginário com Agostinho, perante a figura da verdade muda, Petrarca afirma que o amor é a mais veemente das paixões. Entretanto, seu interlocutor o faz lembrar sua experiência dolorosa com o amor e ressalta que podem ser muitos os males dessa "peste": vontade de lágrimas e suspiros, insônia, desprezo por todas as coisas, ódio pela vida e desejo da morte, solidão, retraimento e tristeza. Prossegue Petrarca (1353):

... os teus olhos pesados e eternamente banhados em pranto; a mente confusa, o descanso do sono atormentado e agitado por dolorosos lamentos, a voz enfraquecida e rouca de tanto chorar; o som das palavras interrompido e quebrado por tudo o que de mais atormentado e dolente se possa imaginar. Parecem-te, esses, sinais de saúde? (p. 237; trad. nossa)

Um contemporâneo de Vieira, que compartilha os pressupostos das tradições agostiniana e tomista, Jean-François Senault (1599/1604-1672), no De l'usage des Passions, afirma também que o amor não pode viver sem repouso, estando sempre em ação e, portanto, consiste na fonte de incontáveis inquietações e experiên- 
cias dolorosas. O amor acredita que tudo pode. Seus desejos movem todas as outras paixões. E, sobretudo, o amor mistura o prazer e a pena. Eis a definição de Senault (1641): "Todas as paixões se elevam para executar seus comandos, e como o movimento da Lua causa o fluxo e o refluxo do mar, assim o movimento do amor causa a paz e a perturbação de nossa alma" (p. 162; trad. nossa).

Um dos efeitos do amor seria a amizade, considerada a doçura da vida que, porém, também comporta penas e dores. Senault (1641) faz das considerações anteriormente citadas de Agostinho, nas Confissões, suas palavras:

As ausências são curtas mortes, e a morte é uma ausência eterna, que nos deixa tantas penas quanto a presença nos dá satisfações: um homem que perde seu amigo, perde a metade de si mesmo, ele é morto e vivo ao mesmo tempo, e a morte apenas se une à vida para torná-la mais miserável. (Senault, 1641, p. 181182 ; trad. nossa)

Mattheus Ribeiro, outro teólogo seiscentista, também enfatiza o quanto o amor confunde o indivíduo, o torna imprudente, o tiraniza, o faz sofrer e pode até mesmo levá-lo ao suicídio, sobretudo porque mistura prazer e dor em uma mesma experiência. Ele afirma (1648): "sendo com razão o Amor veneno doce, enfermidade agradavel, tyrania appetecida, \& morte desejada, constumando aventurar-se a muito porque como cego teme pouco" (p. 47v.).

Ribeiro reconhece que a dor da traição é particularmente aguda, em especial, pelo efeito surpreendente e devastador:

Não nego que a dor de verse hum esposo offendido de sua esposa, seja grande, a aflição penosa, aspera de sofrer, dificil de consolar, (...) com muito mayor razão se deve sentir a offensa causada da pessoa de quem mais se esperava o favor, a ingratidão, de quem mais se esperava o conhecimento, o aggravo de quem se prometia o beneficio. (p. 77)

\section{Os médicos e a dor de amor}

O amor também guarda uma proximidade perigosa com a melancolia, psicopatologia bastante discutida pelos médicos dos séculos XVI e XVII. No entanto, o tema era polêmico desde a Antiguidade. Duminil (1985) levanta alguns problemas na definição do amor como afecção melancólica. Para muitos, o amor não poderia ser a causa da melancolia porque uma das características da melancolia é uma tristeza sem causa. Ao identificar a causa, no amor, o mal não poderia ser mais chamado de melancolia. Também não poderia ser a causa da mania porque o amor causa magreza, e ela não faz parte dos sintomas da mania, segundo vá- 
rios médicos antigos. E ainda há o problema que o amor parece não ser curável e, como na fome e na sede, o seu único remédio encontra-se em si mesmo.

Para Altbauer-Rudnik (2006) apesar de não se diferenciarem muito da tradição antiga, o volume de escritos sobre a melancolia amorosa aumentou consideravelmente no final do século XVI e início do século XVII. De acordo com a literatura médica do período, uma maior predisposição às ligações eróticas estava relacionada ao predomínio do sangue, o que daria ao corpo uma qualidade úmida e quente. Essa inclinação natural, em si mesma, não causa agonia ou dor e contrapõe-se às condições naturais da melancolia, que se caracteriza pelas qualidades fria e seca. Por esse motivo, os afetos melancólicos ocorrem apenas quando, por alguma razão, o amor não pôde ser consumado. $\mathrm{O}$ amor malogrado seca e esfria o corpo, provocando o domínio da bile negra ou melancolia. A atividade mental excessiva, devido aos pensamentos obsessivos sobre o objeto do amor, exacerba o domínio da melancolia, enquanto a perturbação emocional promove a difusão da bile pelo corpo todo, gerando mais desespero e sofrimento.

Um trágico caso de dor de amor é relatado pelo médico romano Alessandro Petronio (1592). Uma jovem teve suas forças vitais minadas pela tristeza de não poder viver um amor, proibido pela família. Muito adoecida, ao receber a visita do amado, a paciente teve uma forte emoção que, segundo Petrônio, apenas apressou a sua morte previamente desencadeada pela dor de amor. ${ }^{2}$

$\mathrm{Na}$ realidade, no início da Idade Moderna, o amor era considerado uma entre outras causas de melancolia ou mania. É o que afirma o influente professor e médico dos soberanos de França, André du Laurens (1558-1609). No Discours de la conservation de la vue, des maladies melancholiques, des catarrhes, \& de la vieillesse, ele explica que a razão é a perturbação do corpo e da alma, o ressecamento dos humores e a alteração da temperatura corporal, em particular, do cérebro (1597, p. 124). Entre os modos de curar os loucos e melancólicos de amor, Laurens, tal como outros autores da época, recomenda operar uma modificação "na crença da coisa amada" (p. 126). Em outras palavras, ele sugere provar ao enfermo quão inconstante e ilusório é o prazer que se pode desfrutar do objeto de desejo.

Robert Burton (1638) escreve que o amor pode inebriar como o vinho, aquecer o corpo e alegrar a alma, mas a melancolia amorosa provoca tormentos,

2. A propósito desse caso e da medicina da alma de Alessandro Petronio, ver Carvalho da Silva, P. J. O tratamento das paixões da alma nos primórdios da medicina moderna: o De victum romanorum de Alessandro Petronio. Revista Latinoamericana de Psicopatologia Fundamental, São Paulo, v. IX, n. 1, p. 64-75, mar.2006. 
preocupações, tristezas, suspeitas, ansiedade e ciúme. Burton também lembra que muitos consideram o ciúme uma causa, outros um sintoma da melancolia, por conta das fantasias suspeitosas que assombram igualmente os ciumentos e os melancólicos. Ele, por sua vez, pensa que o ciúme merece o status de paixão distinta e implica essencialmente o medo de que a pessoa amada esteja interessada em outra pessoa. Muitos ciumentos padecem de receios, tristeza, angústia, ansiedade e ódio pelos mais variados objetos. Conforme Burton, as cortes da Europa oferecem vários exemplos de como o ciúme pode provocar fúria, violência e desespero. ${ }^{3}$

A mais interessante obra desse período sobre o tema da dor de amar é, sem dúvida, o De la maladie d'amour ou mélancholie érotique. Discours curieux qui enseigne à cognoitre l'essence, les causes, les signes et les remedes de ce mal fantastique, do médico francês Jacques Ferrand (1575-1623), editada em Paris, em 1623. Uma primeira versão havia sido publicada em Toulouse, em 1610, porém, após dez anos de circulação, foi queimada nas fogueiras da Inquisição.

Ferrand apresenta uma noção muito semelhante, em alguns aspectos, ao amor mundano de Vieira. Segundo o francês, o amor é composto por diversos movimentos contrários: alegria e tristeza, esperança e desespero, amizade e ódio ou ciúme. É a origem de todas as perturbações da alma ou uma síntese das mesmas: desejando gozar de algo que lhe agrada ocorre a concupiscência; não podendo gozar há a dor e o desespero. Quando consegue é o prazer, quando acredita na possibilidade é a esperança, mas quando a perde, o ciúme.

Ferrand (1623) declara que o amor é cego porque afeta o julgamento e a imaginação. Em suas palavras: "Nós diríamos, portanto, sob esses fundamentos, que o amor ou a paixão erótica é uma espécie de devaneio, procedente de um desejo desregrado de gozar da coisa amada, acompanhado de medo e de tristeza" (p. 26; trad. nossa). Esse devaneio pode, porém, causar febre, alterações dos batimentos cardíacos e no rosto, apetites depravados, tristeza, suspiros, lágrimas sem motivo, fome insaciável, sede enraivecida, opressões, sufocações, insônia, melancolia, raiva, furor uterino, entre outros desconfortos.

Além de se valer de muitos exemplos retirados de médicos, filósofos e poetas, tanto antigos, como modernos, Ferrand relata um caso, pelo que parece, de sua própria experiência clínica. Ele afirma ter examinado o paciente no mês de

3. Um paralelo: J.-D. Nasio (1997, p. 66) afirma que o ciúme é uma variante da dor psíquica. É um afeto que engloba a dor de ter perdido o amor do amado, a integridade da imagem narcísica, o ódio contra o rival e as auto-acusações por não ter sabido manter o lugar na ligação amorosa.

Rev. Latinoam. Psicopat. Fund., São Paulo, v. 11, n. 3, p. 475-487, setembro 2008 
maio de 1604, em Agen, sua cidade natal, quando ainda iniciava o exercício da medicina:

... ele não podia dormir, nada no mundo o agradava, estava tão inquieto que teve de se mudar de Toulouse para Agen, na esperança que uma mudança de lugar apaziguasse seu mal, onde, pelo contrário, ele se encontrava em pior estado, desgostoso e alterado. Eu observei um jovem triste, sem causa aparente, que algum tempo antes eu via jovial; notei um rosto pálido, amarelado e desbotado, os olhos afundados, mas o resto do corpo em bom estado. (p. 92; trad. nossa)

Considerando sua idade, temperamento e sua profissão, Ferrand conclui que ele estava doente de amor:

E quando eu tentava descobrir a causa externa de sua doença, uma jovem trazia a lamparina. Ao tomar seu pulso, que desde o início variava de diferentes formas, eu o vi ruborescer e quase não conseguir falar. Finalmente, ele fala sobre seu mal: mas quer apenas se curar por meio daquela que o fere. Por isso, pedeme para que eu solicite a mão da moça à sua mãe, fiando-se que seu pai não the negaria esse contentamento. (...) Esse casamento não podendo se realizar, ele se desespera, sofre de febre, com uma grande expulsão de sangue: isso o surpreende e o induz a seguir meu conselho, e por meio dos remédios da medicina obtém a cura de seu mal. (p. 93-94; trad. nossa)

Ferrand também apresenta indagações particularmente interessantes para o campo da psicopatologia, tais como se homens e mulheres amam na mesma intensidade ou se o ciúme é sinal de amor ou de patologia.

Mesmo suas estranhas teorias sobre a misteriosa anatomia feminina testemunham de uma observação de que homens e mulheres sentem de modo diferente porque são constituídos anatomicamente de modo diverso. Ou ainda que, por uma questão de justiça com as mulheres, a natureza as teria dotado de prazeres mais intensos para compensar as dores sofridas durante a gravidez e o parto. Em síntese, as mulheres têm naturalmente o direito ao prazer e não apenas à dor no amor. Aliás, não falta desejo sexual às damas:

Mesmo que os homens pareçam, primeiramente, mais inclinados à lubricidade, não isentaremos as mulheres do mesmo desejo. Acontece que elas o escondem o quanto podem, no que se assemelham aos alambiques, gentilmente colocados sobre o fogo de modo que não o vemos. Mas, se olharmos debaixo do alambique, isto é, colocarmos a mão no coração das Damas, encontraremos nos dois lugares um grande braseiro. (p. 163-164; trad. nossa)

$\mathrm{Na}$ tentativa de curar a dor de amor, recomendava-se, na Renascença, além das conversas com amigos e da escuta de músicas, a própria prática sexual moderada (Simoni, 1985, p. 88). O já citado médico romano Petronio é francamente

Rev. Latinoam. Psicopat. Fund., São Paulo, v. 11, n. 3, p. 475-487, setembro 2008 
a favor, guardando-se a moderação e a moral. Ferrand, por sua vez, admite que médicos antigos e modernos afirmam que não haveria melhor remédio para o mal do amor do que gozar da presença da pessoa amada, mesmo em sonho, mas se deve considerar, em primeiro lugar, se tal união é lícita ou ilícita. Sua posição é que não se cura um vício com outro vício, mas com uma virtude. Ele considera igualmente perigosa a idéia de fazer enamorar-se por várias pessoas até ficar cansado do amor. Isso poderia criar um mau hábito de amar indiferentemente.

Como vários autores antigos, um dos remédios propostos por Ferrand consiste em mostrar que o amor se alimenta de uma ilusão. Nesse sentido, é recomendável tomar cuidado com a força da beleza das mulheres, o que pode ser uma mera ilusão criada nos próprios olhos de quem ama. Assim, se for possível convencer o amante de que ele se engana em relação à beleza dessa mulher, aumentando os defeitos físicos da amada e mesmo enfatizando suas faltas morais (isso cabe mais aos teólogos, na realidade), será possível curar o amor. Ferrand (1623) lembra, porém, que isso pode, pelo contrário, agravar ainda mais o amor. Outra possibilidade seria converter o amor em ódio, persuadindo que ele não é amado e que todas as manifestações de amor eram falsas. Ainda se pode revelar aos homens as dissimulações das mulheres e às mulheres os perigos, para a sua honra, que os homens representam.

Deve-se, sobretudo, evitar os passatempos conjuntos e todas as facilitações do contato entre as pessoas, porque são ocasiões para ocorrer o amor: "Passase à freqüentação, e à amizade honesta: dessa amizade, ao amor apaixonado: e do amor, converte-se ao gozo. (...) a uns perverte o julgamento, perturba a imaginação de outros, e sob a aparência de um sono doce, os envolve com mil verdadeiras penas" (p. 189; trad. nossa).

Para temperar esse afeto que se mostra doce, mas se revela penoso, também se recomenda suscitar as paixões da tristeza e do medo. O que mostra o quão problemática é a dor do amor e o quão difícil é o seu tratamento: curar dor com dor?

Ferrand finaliza seu livro e suas prescrições contra os males do amor como um autêntico médico da alma: quando nada disso funciona, vale sempre a sabedoria e a prudência. O que, no fundo, não é muito diferente das idéias defendidas por Vieira sobre a dor do amor em diversos púlpitos do mundo português.

Se, por um lado, havia quem questionasse a legitimidade do amor humano por causa, entre outras razões, de sua natureza incerta e inquietante, havia também quem admitisse que o ciúme moderado, efeito mais doloroso dessa mesma incerteza, poderia, inclusive, sinalizar o verdadeiro amor. Mesmo sendo, como Ferrand (1623) afirmou, "uma paixão engenhosa que, freqüentemente, tira de um mal imaginário uma viva e verdadeira dor" (p. 145; trad. nossa), o ciúme testemunha o caráter particularmente provocativo da paixão erótica. 
Ora, para poder amar sem adoecer é necessário suportar a dor de estar na dependência do outro e a incerteza de uma correspondência possível, além de saber lidar com as fantasias mais primitivas que se renovam a cada encontro. Ao contrário do que fazem crer as publicidades nas vésperas da celebração do dia dos namorados, tanto a história quanto a clínica psicanalítica mostram que o amor é tudo menos pura harmonia, paz e aconchego certo. O amor humano é parcial, instável, finito. O próprio Freud (1930) adverte, em "O mal-estar na cultura": "nunca nos achamos tão indefesos contra o sofrimento como quando amamos, nunca tão desamparadamente infelizes como quando perdemos o nosso objeto amado ou o seu amor" (p. 441).

Finalmente, Jacques Ferrand é um bom exemplo de alguém que estava, no mínimo, atento à dinâmica, ao mesmo tempo, profundamente enriquecedora e perturbadora do amor. Seu livro aponta para como o amor reside, muitas vezes, no tênue limite entre a paixão e a psicopatologia. O que torna a experiência amorosa ainda mais tentadora.

\section{Referências}

Agostinho. Les confessions. Edição bilingue latin francês de E. Tréhorel e G. Bouissou. Paris: Institut d'Études Augustiniennes, 1998.

AltBAuer-RudniK, M. Love, madness and social order: love melancholy in France and England in the late sixteenth and early seventeenth centuries. Gesnerus. Swiss Journal of the History of Medicine and Sciences, Basel, v. 63, p. 33-45, 2006.

Assis, R.M. A fineza do amor nos sermões do mandato do Padre Antônio Vieira. In: Massimi, M.; SiLVA, P.J.C. (Orgs.). Os olhos vêem pelo coração. Conhecimentos psicológicos das paixões na cultura luso-brasileira dos séculos XVI e XVII. Ribeirão Preto: Holos/Fapesp, 2001. p. 65-77.

Burton, R. The anatomy of melancholy: what it is, with all the kinds, causes, symptomes, prognostickes and severall cures of it (...). Oxford: Cripps, 1638.

Carvalho da Silva, P. J. O tratamento das paixões da alma nos primórdios da medicina moderna: o De victum romanorum de Alessandro Petronio. Revista Latinoamericana de Psicopatologia Fundamental, São Paulo, v. IX, n. 1, p. 64-75, mar.2006.

Cícero, T. Tusculanae Disputationes. In: Les Stoïciens I. Tradução francesa de E. Bréhier. Paris: Gallimard, 1962. p. 291-404.

Du Laurens, A. Discours de la conservation de la vue, des maladies melancholiques, des catarrhes, \& de la vieillesse. Paris: Jamet Mettayer, 1597. 
Duminil, M.-P. La mélancolie amoureuse dans l'Antiquité. In: CÉARD, J. (Org.). La folie et le corps. Paris: Presses de l'École Normale Supérieure, 1985. p. 91-109.

Ferrand, J. De la maladie d'amour ou mélancholie érotique. Discours curieux qui enseigne à cognoitre l'essence, les causes, les signes et les remedes de ce mal fantastique. Paris: Denis Moreau, 1623.

Freud, S. (1930). Das Unbehagen in der Kultur. Gesammelte Werke. Frankfurt am Main: Fischer Verlag, 1981. v. XIV, p. 421-513.

Nasio, J.-D. O livro da dor e do amor. Trad. de L. Magalhães. Rio de Janeiro: Jorge Zahar, 1997.

OvíDio. L'Art d'aimer. Les Remèdes à l'amour. Les produits de beauté pour le visage de la femme. Trad. francesa de H. Bornecque. Paris: Gallimard, 2007.

Petrarca, F. (1353). Il mio segreto (Secretum). Edição bilingue latina-italiana por U. Doti. Milano: Biblioteca Universali Rizzoli, 2000.

Petronio, A. Del viver delli romani et di conservar la sanità. Roma: Domenico Basa, 1592.

Ribeiro, M. Alivio de tristes e consolação de queixosos. Lisboa: Manoel Da Sylva, 1648. Senault, J.-F. (1641). De L'usage des passions. Paris: Fayard, 1987.

Simoni, M. Aegritudo amoris et res literaria à la Renaissance: Réflexions préliminaires. In: CÉARD, J. (Org.). La folie et le corps. Paris: Presses de l'École Normale Supérieure, 1985. p. 83-90.

TomÁs de Aquino. Suma Teológica. Edição latino-portuguesa de A. Correia. São Paulo: Siqueira, 1954. v. 12, I parte da II parte - Questões 18-48.

VIEIRA, A. (1643-1644). Sermões. Porto: Lello e Irmão, 1951. 15 v.

\section{Resumos}

(El dolor de amor en la medicina del alma de la primera modernidad)

Este artículo discute el problema del dolor de amor en los diferentes campos del saber que formaran parte de la medicina del alma de la primera modernidad. Se dio especial destaque a las reflexiones del médico francés Jacques Ferrand (1575-1623) sobre el carácter inestable, ilusorio y en falta del amor. Se concluye que el dolor de amor exige pensar las relaciones entre afectos y el cuerpo, así como desafiar las propias categorías diagnósticas y los tratamientos tradicionales.

Palabras clave: Dolor de amor, melancolía, celos, medicina del alma, historia de la psicopatología

Rev. Latinoam. Psicopat. Fund., São Paulo, v. 11, n. 3, p. 475-487, setembro 2008 
(La douleur d'amour dans la médecine de l'âme de la première modernité)

Cet article analyse le problème de la douleur d'amour dans les divers champs du savoir qui constituèrent la médecine de l'âme de la première modernité. En particulier, on analyse les considérations du médecin français Jacques Ferrand (1575-1623) à propos de la nature instable, illusoire et imparfaite de l'amour. On conclu que la douleur d'amour exige penser les rapports entre le corps et les affects, d'autant plus qu'elle représente un défi pour les catégories diagnostiques et cures traditionnelles.

Mots clés: Douleur d'amour, mélancolie, jalousie, médecine de l'âme, histoire de la psychopathologie

(The pain of love in the medicine of the soul of the first modenity)

This article discusses the topic of the pain of love in different fields of knowledge that were part of the medicine of the soul during the first modernity. In particular, the author analyzes the considerations of the French physician Jacques Ferrand's (15751623) regarding the unstable, delusional and imperfect nature of love. The conclusion is that the pain of love calls for reflections on the relationship between affects and the body, and challenges traditional categories of diagnosis and treatment.

Key words: Pain of love, melancholia, jealousy, medicine of the soul, history of psychopathology

Versão inicial recebida em junho de 2008

Versão aprovada para publicação em junho de 2008

\section{Paulo José Carvalho da Silva}

Psicólogo; psicanalista; mestre em História da Ciência pela Pontifícia Universidade Católica de São Paulo - PUC-SP; doutor em Psicologia pela Universidade de São Paulo - USP (São Paulo, SP, Brasil); professor doutor do Programa de Estudos Pós-Graduados em História da Ciência, Pontifícia Universidade Católica de São Paulo - PUC-SP (São Paulo, SP, Brasil), membro da Associação Universitária de Pesquisa em Psicopatologia Fundamental (São Paulo, SP, Brasil).

Rua Cajaíba, 15

05025-000 São Paulo, SP, Brasil

Fone: (11) 9248-9202

e-mail: paulojcs@hotmail.com 